\title{
Individual and contextual determinants of exclusive breast-feeding in São Paulo, Brazil: a multilevel analysis
}

\author{
Sonia Isoyama Venancio ${ }^{1, *}$ and Carlos Augusto Monteiro ${ }^{2}$ \\ 'Núcleo de Investigação em Nutrição, Instituto de Saúde, Secretaria de Estado da Saúde de São Paulo, Rua Santo \\ Antônio 590, $3^{\circ}$ andar, Bela Vista, São Paulo, CEP $01314-000$, Brazil: ${ }^{2}$ Departamento de Nutrição da Faculdade \\ de Saúde Pública, Universidade de São Paulo, São Paulo, Brazil
}

Submitted 16 November 2004: Accepted 12 May 2005

\begin{abstract}
Objective: To identify individual and contextual factors associated with the practice of exclusive breast-feeding (EBF).

Methodology: We analysed 34435 children under 6 months of age living in 111 municipalities in the state of São Paulo, south-eastern Brazil, who participated in a survey investigating feeding practices during the first year of life, carried out during the 1999 national vaccination campaign. The questionnaire employed included questions on the consumption, in the last $24 \mathrm{~h}$, of breast milk, water, tea, other types of milk and other foods, in addition to mother and child characteristics. Information on the pro-breast-feeding measures implemented in the municipalities was also collected. The effects of individual and contextual characteristics on EBF were analysed using multilevel models.

Results: The final model showed a greater chance of EBF in women with tertiary education (odds ratio $(\mathrm{OR})=1.91 ; 95 \%$ confidence interval $(\mathrm{CI}) 1.75-2.06$ ); women aged between 25 and 29 years (OR $=1.52$; 95\% CI 1.41-1.63); multiparae $(\mathrm{OR}=1.42 ; 95 \%$ CI $1.33-1.49)$; female babies (OR $=1.12 ; 95 \%$ CI $1.05-1.18)$; birth weight $\geq 3000 \mathrm{~g}(\mathrm{OR}=1.73 ; 95 \%$ CI $1.49-1.97)$; child follow-up in the private healthcare network (OR $=1.10 ; 95 \%$ CI 1.02-1.18); and municipalities with four or five probreast-feeding measures ( $\mathrm{OR}=2.4 ; 95 \% \mathrm{CI} 2.19-2.88$ ). An analysis of the interactions between individual and contextual variables showed that the presence of at least four pro-breast-feeding measures in the municipality attenuated the risk of early termination of EBF associated with low maternal schooling and low birth weight, and transformed child follow-up in the public network into a protective factor against the early termination of breast-feeding.

Conclusions: The presence of measures aimed at protecting, promoting and supporting breast-feeding in the municipality had a positive influence on EBF and attenuated the impact of risk factors for the termination of breast-feeding.
\end{abstract}

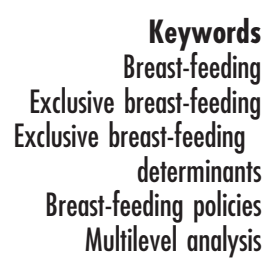

Keywords
Breast-feeding Exclusive breast-feeding determinants Multilevel analysis
The advantages of exclusive breast-feeding (EBF) during the first 6 months of life have become increasingly evident since the 1980s. A study carried out in Brazil showed that non-breast-fed children had a 14-fold risk of dying from diarrhoea and a 3.6-fold risk of dying from respiratory disease in the first year of life compared with children who were exclusively breast-fed ${ }^{1}$. César et al. ${ }^{2}$ showed that the probability of hospital admission due to pneumonia among non-breast-fed children was 17 times greater in the first year and 61 times greater in the first 3 months of life compared with exclusively breast-fed children. In an analysis of the effect of breast-feeding on infant mortality in 16 Latin-American countries, Betrán et al. ${ }^{3}$ concluded that $66 \%$ of deaths caused by diarrhoea and respiratory infections in the region could be prevented by EBF in the first 4 months of life. After reviewing the costs and benefits of EBF in Brazil, Honduras and Mexico, Sanghvi ${ }^{4}$ concluded that promoting breast-feeding is one of the most advantageous health interventions available.

Although there are positive trends in breast-feeding practices in Brazil ${ }^{5}$, only a minority of children receive breast milk exclusively during the first 6 months of life, as recommended by the World Health Organization (WHO) ${ }^{6,7}$.

Studies of the determinants of EBF are scarce and have limited themselves to analysing the influence of individual attributes (of children and/or mothers) on this practice, failing to consider contextual variables, such as the activity of public health-care services and the socio-economic and demographic characteristics of the municipalities where the children live.

The present study examines the influence of individual and contextual factors on the frequency of EBF in children 
aged up to 6 months living in 111 municipalities of the state of São Paulo, in south-eastern Brazil.

\section{Methods}

\section{Study population}

The population of the present study corresponded to all children under the age of 6 months who attended the vaccination clinics of 111 municipalities in the state of São Paulo during the 1999 national vaccination campaign.

In municipalities with infant populations of up to about 1500 children (estimated based on data from the 1998 vaccination campaign), all infants who attended vaccination clinics were studied. For the remaining municipalities, samples of children under 1 year of age were studied, adopting a two-stage clustering sampling ${ }^{8}$. In the first stage, vaccination clinics were randomly selected, the probability of a clinic being selected being proportional to the number of children vaccinated there in the preceding year. In the second stage, children from within each clinic were systematically selected. The sample is equiprobabilistic, or self-weighted, since the sampling fraction remains constant based on the expression $f=f_{1} \times f_{2}$; that is, all children have the same probability of being included in the selected sample.

A final total of 34435 children under 6 months of age were studied.

\section{Data collection procedure}

Teams attended $8 \mathrm{~h}$ training sessions addressing survey organisation at the local level, sampling and questionnaire administration. Standardised questionnaires were answered by mothers or caregivers, and were administered by properly trained interviewers. The questionnaires included questions on consumption, in the $24 \mathrm{~h}$ preceding the interview, of the following items: breast milk, other types of milk (formula, fluid), water, tea, juice, fruit and other foods (porridge, paps or salt meals), following WHO recommendations for breast-feeding surveys 9 . In addition, questionnaires also contained questions regarding birth weight, mode of delivery, delivery in a hospital participating in the 'Baby-Friendly Hospital Initiative' and maternal data (age, parity, schooling, working situation, and use of private or public health-care networks for the baby).

Information on conditions that protect, promote and support breast-feeding in the municipalities was obtained by a questionnaire that was answered by the local research coordinators. This questionnaire included questions on the development of municipal measures for the promotion of breast-feeding, which mostly reflect the directives proposed by the Brazilian Ministry of Health for the construction of an inclusive policy for promoting breastfeeding ${ }^{10}$. These included: (1) the presence of a formal (written) municipal policy for breast-feeding; (2) activities for monitoring the Brazilian Norm for the
Commercialization of Foods for Lactating Infants; (3) participation in World Breastfeeding Week; (4) the presence of a 'Baby-Friendly' hospital (BFH); (5) the presence of a human milk bank; (6) attendance of healthcare professionals at the $18 \mathrm{~h}$ Breastfeeding Management Course or the Breastfeeding Counseling Course; (7) the presence of a multi-professional group dedicated to the promotion of breast-feeding or to research on the subject; and (8) conducting surveys to measure the prevalence of breast-feeding.

\section{Study variables}

Children under 6 months of age who had received breast milk in the previous $24 \mathrm{~h}$ without any other foods or fluids were considered as belonging to the EBF group, as recommended by $\mathrm{WHO}^{9}$.

The following child characteristics were studied: sex (male/female); birth weight (up to $1499 \mathrm{~g}, 1500-1999 \mathrm{~g}$, 2000-2499g, 2500-2999g, 3000 g and over); mode of delivery (vaginal/Caesarean section); hospital of birth $(\mathrm{BFH} / \mathrm{not} \mathrm{BFH})$; and age group as control variable. Mother's characteristics studied were: age (11-17 years, 18-19 years, 20-24 years, 25-29 years, 30-34 years, 35 years and older); parity (primiparous/multiparous); working situation (housewife, formal labour, informal labour); schooling (incomplete primary, complete primary, incomplete secondary, complete secondary, complete/incomplete tertiary education); and type of service used for infant care (public/private networks).

Municipalities were characterised in terms of location (inner-state/metropolitan area of São Paulo City); population (up to $10000,10000-50000,50000-100,000$, 100000 or more inhabitants) based on to data provided by the São Paulo State Secretariat of Health; and IPRS, a human development index considering population longevity, schooling and municipal economic development, which rates municipalities according to a scale ranging from 1 to 5, where municipalities in better and worse stages of development receive scores 1 and 5 , respectively ${ }^{11}$.

Additionally, the intensity of the municipality's investment in breast-feeding was characterised as the total number of municipal pro-breast-feeding measures reported by local survey coordinators. The number of measures in the 111 municipalities ranged from zero to five. Three categories were therefore created for this variable: 0-1 measure, $2-3$ measures and 4-5 measures.

\section{Analytical procedures}

Estimates of EBF in relation to the child's age and their respective 95\% confidence intervals (95\% CI) were obtained by logistic regression, which estimates the probability $P(y=1)$ of breast-feeding at a given age as a logistic function: $P(y+1)=1 /[1+\exp (-\alpha-\beta x)]$, where $\alpha$ and $\beta$ are regression coefficients and $x$ is age ${ }^{12}$.

Two types of explanatory variables were considered in the analysis of the determinants of EBF: those related to 
attributes of the mother and child (individual explanatory variables) and those related to the municipalities in which the children lived (contextual explanatory variables).

The study of individual factors related to the practice of EBF was carried out concomitantly to a contextual analysis, in a multilevel analysis model ${ }^{13}$. Studies of this kind are also termed 'mixed studies', given that they investigate the effects of independent ecological variables over individual-level dependent variables ${ }^{14}$.

Multilevel analysis is based on the concept that individuals interact with social contexts into which they are inserted, and that the characteristics of these social groups, on the other hand, are influenced by the individuals that compose them. In a multilevel study, the structure of data in the population is hierarchic and sampling data are seen as samples of several stages of this hierarchical population.

Traditional regression models are based on the assumption that the subjects in a study are independent among themselves in relation to the studied outcome. When data are structured in hierarchies, units in the same group are rarely independent. The fact that the units share an environment, or that they are more similar among themselves than in relation to other units, may lead to greater similarity also in terms of the outcomes of interest. This problem is more important still when explanatory variables from higher levels in the hierarchy are of interest, so that all units in the group are exposed to the factor in an identical fashion ${ }^{13}$. Multilevel models are developed in order to overcome the analytical difficulties that arise when data are organised hierarchically and there is an intra-group correlation ${ }^{13}$.

For the multilevel analysis carried out in the present study, explanatory variables were divided into two levels, Level 1 containing individual characteristics (of both mother and child) and Level 2 containing variables that characterise the municipal context, the outcome being EBF (yes/no).

Individual variables were included in the model following a hierarchical modelling strategy. In this approach, variables are placed into hierarchies according to a previously established conceptual framework, and the choice of criteria for selecting variables stretches beyond purely statistical considerations. The hierarchical structure of independent variables is maintained during data analysis, allowing for the selection of variables more strongly associated with the outcome of interest ${ }^{15,16}$.

Modelling in stages was then undertaken, employing a backwards selection strategy within each level of the hierarchical model. Of the variables in Level 1, maternal schooling was introduced in the first stage of modelling, being adjusted only for child's age (Block 1). In the next two stages, variables related to maternal attributes (Block 2) and child attributes (Block 3) were subsequently included. The inclusion of contextual variables (Level 2) took place in the last stage of modelling. We chose to include in the initial model all variables that, in univariate analysis, showed a $P$-value below 0.15 .

One of the advantages of multilevel modelling, mentioned by $\operatorname{Hox}^{17}$, is the possibility of analysing the interactions between variables describing individuals and those describing social groups. For the analysis of interactions between individual and contextual variables, the outcome considered was the interruption of EBF, so as to allow us to identify potential reductions in the risk of interrupting EBF associated with individual characteristics related to the effect of changes in contextual determinants. Data analysis was performed using MLwiN 1.1 software, employing a multilevel logistic regression model with generalised least-squares estimation ${ }^{18}$. The statistical significance of each variable in the multilevel logistic regression was analysed by Wald's test ${ }^{19}$.

The present study was approved by the Research Ethics Committee of the School of Public Health of the University of São Paulo.

\section{Results}

Estimates of the frequency of EBF at selected ages are presented in Table 1. The frequency of EBF was already low at the end of the first 15 days of life (32\%), fell further still at age 90 days (12\%) and was minute at around 6 months of age (4\%).

The prevalence of EBF between 0 and 6 months found in the 111 municipalities was 13.9\% (95\% CI 13.6-14.3). There was a wide variation in this indicator among the municipalities studied. Figure 1 presents the distribution of municipalities according to intervals of frequency of EBF in children under 6 months old.

Table 2 presents the variables that compose the final model of individual and contextual determinants of EBF in children below 6 months of age and their corresponding odds ratios (OR). The individual variable mother's working situation and the contextual variables location, population and IPRS were not included in multilevel

Table 1 Estimates of the frequency of exclusive breast-feeding (EBF) and their respective confidence intervals $(95 \% \mathrm{Cl})$ at selected ages among children living in 111 municipalities of the state of São Paulo, 1999

\begin{tabular}{lccc}
\hline Age (days) & $n$ & EBF $(\%)$ & $95 \% \mathrm{Cl}$ \\
\hline 1 & 23 & 36.88 & $29.84-43.93$ \\
15 & 180 & 31.81 & $25.65-37.98$ \\
30 & 219 & 26.83 & $20.62-33.03$ \\
45 & 196 & 22.36 & $16.63-28.10$ \\
60 & 203 & 18.44 & $13.16-23.73$ \\
75 & 207 & 15.10 & $9.57-20.63$ \\
90 & 161 & 12.26 & $7.80-16.72$ \\
105 & 208 & 9.89 & $5.81-13.98$ \\
120 & 205 & 7.94 & $4.11-11.78$ \\
135 & 191 & 6.35 & $3.28-9.41$ \\
150 & 243 & 5.06 & $2.20-7.91$ \\
165 & 226 & 4.02 & $1.13-6.90$ \\
\hline
\end{tabular}




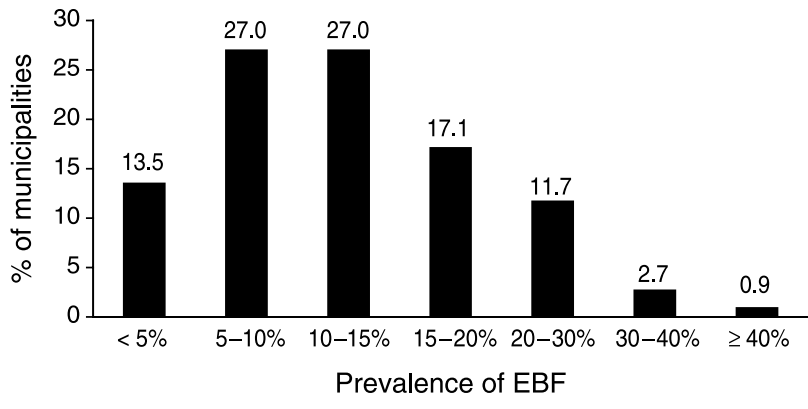

Fig. 1 Percentage of municipalities according to prevalence of exclusive breast-feeding (EBF) among children under 6 months of age in 111 municipalities of the state of São Paulo, 1999

analysis, as they were not significantly associated with EBF in univariate analysis.

The variable mother's schooling, adjusted for the child's age, showed a 'dose-response-like' effect on the outcome, i.e. the greater the mother's schooling, the greater the chance of the child being exclusively breast-fed. The children of women with complete or incomplete tertiary education were almost twice more likely to be exclusively breast-fed than the children of mothers who had not completed primary education.

Mother's age was significantly associated with EBF $(P=0.000)$. It is interesting to note that there was an increase in the chance of EBF with increasing mother's age until the 25-29 years age group, after which the OR levelled out and even decreased slightly in the 35+years category. Multiparity was also significantly associated with $\mathrm{EBF}(\mathrm{OR}=1.42)$ after adjustment for the variables in Block 1 and mother's age.

There was a statistically significant association between $\mathrm{EBF}$ and female children $(\mathrm{OR}=1.12)$. The association between EBF and birth weight was significant, also showing a dose-response-like effect. Children whose follow-up took place in the private health-care network showed a greater chance of EBF $(\mathrm{OR}=1.10)$ compared with those who attended public network facilities. The mode of delivery and type of hospital in which the child was born (BFH or not) did not reach statistical significance after adjustment for the variables in Blocks 1 and 2 and for the remaining variables in Block 3, and were thus removed from the final model.

Table 2 Individual and contextual determinants of exclusive breast-feeding and corresponding odds ratios (OR) and confidence intervals $(95 \% \mathrm{Cl})$ obtained by multilevel hierarchical analysis among children under 6 months of age from 111 municipalities of the state of São Paulo, 1999

\begin{tabular}{|c|c|c|c|c|}
\hline Level/hierarchical block & Variable & OR & $95 \% \mathrm{Cl}$ & $P$-value \\
\hline \multirow[t]{6}{*}{$1 / 1$} & Maternal schooling & * & & 0.000 \\
\hline & Incomplete primary & 1.00 & & \\
\hline & Complete primary & 1.15 & $1.05-1.26$ & \\
\hline & Incomplete secondary & 1.18 & $1.07-1.30$ & \\
\hline & Complete secondary & 1.58 & $1.49-1.67$ & \\
\hline & Complete/incomplete tertiary & 1.91 & $1.75-2.06$ & \\
\hline \multirow[t]{10}{*}{$1 / 2$} & Mother's age & $\dagger$ & & 0.000 \\
\hline & $11-17$ years & 1.00 & & \\
\hline & $18-19$ years & 1.17 & $1.03-1.31$ & \\
\hline & $20-24$ years & 1.43 & $1.33-1.54$ & \\
\hline & $25-29$ years & 1.52 & $1.41-1.63$ & \\
\hline & $30-34$ years & 1.52 & $1.40-1.64$ & \\
\hline & $35+$ years & 1.22 & $1.06-1.39$ & \\
\hline & Parity & & & 0.000 \\
\hline & Primiparous & 1.00 & & \\
\hline & Multiparous & 1.41 & $1.33-1.49$ & \\
\hline \multirow[t]{12}{*}{$1 / 3$} & Child's sex & $\ddagger$ & & 0.001 \\
\hline & Male & 1.00 & & \\
\hline & Female & 1.12 & $1.05-1.18$ & \\
\hline & Birth weight & & & 0.000 \\
\hline & $<1500 \mathrm{~g}$ & 1.00 & & \\
\hline & $1500-1999 \mathrm{~g}$ & 1.15 & $0.71-1.59$ & \\
\hline & $2000-2499 \mathrm{~g}$ & 1.29 & $1.01-1.57$ & \\
\hline & $2500-2999 \mathrm{~g}$ & 1.52 & $1.27-1.77$ & \\
\hline & $3000+g$ & 1.73 & $1.49-1.97$ & \\
\hline & Out-patient follow-up & & & 0.025 \\
\hline & Public network & 1.00 & & \\
\hline & Private network & 1.10 & $1.02-1.18$ & \\
\hline \multirow[t]{3}{*}{$2 /-$} & Total number of pro-breast-feeding measures & $\S$ & & 0.000 \\
\hline & $\begin{array}{l}0-1 \text { measure } \\
2-3 \text { measures }\end{array}$ & $\begin{array}{l}1.00 \\
118\end{array}$ & $0.87-1.49$ & \\
\hline & 4-5 measures & 2.53 & $2.19-2.88$ & \\
\hline
\end{tabular}

* OR adjusted for child's age group.

† OR adjusted for child's age group, for variables in hierarchical block 1 and for remaining variables in hierarchical block 2.

$\ddagger$ OR adjusted for child's age group, for variables in hierarchical blocks 1 and 2 , and for remaining variables in hierarchical block 3.

§OR adjusted for child's age group and for variables in hierarchical blocks 1, 2 and 3. 
It is interesting to note that, regardless of the effect of individual variables, the contextual variable total number of pro-breast-feeding measures was significantly associated with $\mathrm{EBF}$, the children living in municipalities with better conditions ( $4-5$ measures) being 2.5 times more likely to be exclusively breast-fed than those living in municipalities with worse conditions.

Table 3 presents the results of interactions between the contextual variable total number of pro-breast-feeding measures and individual variables. The statistical hypothesis that we sought to test by introducing the interaction terms in the model was whether living in a municipality with a good performance in terms of the implementation of pro-breast-feeding measures (4-5 measures) could reduce the influence of certain individual attributes on the risk of interruption of breast-feeding the child (absence of EBF).

The final model with interactions allowed us to calculate the OR for the interruption of breast-feeding associated with each of the individual attributes and within the contextual condition of residency in municipalities with worse ( 0 -3 measures) or better (4-6 measures) performance with regard to the implementation of pro-breastfeeding measures. We found that the contextual condition of living in a municipality with better performance reduced the negative impact of low maternal schooling and low birth weight on EBF. This condition also modified the effect of the variable use of public health-care network, rendering it a protective factor for EBF.

\section{Discussion}

Worthy of note in the present study are the low frequency of EBF in children under 6 months of age and the great variation in this indicator across the 111 municipalities studied. Likewise, the results of a study coordinated by the Brazilian Ministry of Health in Brazilian capitals in $1999^{20}$ showed a low prevalence of EBF in children under age 4 months (35.6\%) and, similarly to what was verified in the present study, detected a wide variation in the scenario of EBF in Brazil.

Regarding socio-economic conditions, we found that greater maternal schooling favoured the maintenance of EBF. Likewise, the last population-based study conducted in Brazil $^{21}$ showed that median duration of breast-feeding was below 1 month among women with less than 3 years of schooling and about 2 months in women with 12 or more years of schooling. A prospective study carried out by Pérez-Escamilla et $a l^{22}$ in municipalities of different countries (Santos/Brazil, Mexico City/Mexico, San Pedro Sula and Tegucigalpa/Honduras) showed that EBF was more frequent among women of high socio-economic level in the municipality of Santos in São Paulo State, the opposite being observed in Mexican and Honduran municipalities. In the city of Benin, in Nigeria, no association was found between women's socio-economic conditions and the duration of $\mathrm{EBF}^{23}$. These findings indicate a need for further studies, in different cultural contexts, in order to better investigate the association between the practice of breast-feeding and socioeconomic variables.

We found a statistically significant association between maternal age and EBF. These data confirm the results of the collaborative study conducted in Brazil, Mexico and Honduras $^{22}$, in which a greater tendency towards EBF among women older than 18 years was identified only among Brazilian women. Regarding parity, there was a greater chance of EBF among multiparae. There is no consensus in the literature as to the effect of parity on breast-feeding $^{24,25}$, and little is known about the influence of this attribute on EBF.

Girls had a greater chance of being exclusively breastfed than boys. This finding is in agreement with the findings of Pérez-Escamilla et al. ${ }^{22}$ in Brazil and Honduras. The authors discuss the possibility of there being a belief among health-care professionals and/or mothers that boys have greater nutritional needs, and thus require complementary feeding from an earlier age. A similar finding

Table 3 Risk factors for interruption of exclusive breast-feeding (EBF), with and without the effect of the interaction with the variable 'total number pro-breast-feeding measures', among children under 6 months of age from 111 municipalities of the state of São Paulo, 1999

\begin{tabular}{|c|c|c|c|}
\hline \multirow[b]{2}{*}{ Hierarchical block } & \multirow[b]{2}{*}{ Risk factor } & \multicolumn{2}{|c|}{ OR for interruption of EBF } \\
\hline & & With 0-3 measures & With 4-5 measures \\
\hline 1 & Schooling ( $<8$ years) & $1.53^{*}$ & $1.33^{*}$ \\
\hline \multirow[t]{2}{*}{2} & Mother's age ( $<18$ years) & $1.44 \dagger$ & $1.44 \dagger$ \\
\hline & Parity (primiparous) & $1.34 \dagger$ & $1.34 \dagger$ \\
\hline \multirow[t]{3}{*}{3} & Child's sex (male) & $1.11 \ddagger$ & $1.11 \ddagger$ \\
\hline & Birth weight (low) & $1.60 \ddagger$ & $1.20 \ddagger$ \\
\hline & Use of public network & $1.26 \ddagger$ & $0.89 \ddagger$ \\
\hline \multicolumn{4}{|c|}{$\begin{array}{l}\text { OR - odds ratio. } \\
\text { *OR adjusted for child's age and total number of municipal pro-breast-feeding measures. } \\
\text { †OR adjusted for child's age, variables in hierarchical block } 1 \text {, remaining variables in hierarchical block } 2 \text {, } \\
\text { and total number of municipal pro-breast-feeding measures. } \\
\text { † OR adjusted for child's age, variables in hierarchical blocks } 1 \text { and } 2 \text {, remaining variables in hierarchical } \\
\text { block } 3 \text {, and total number of municipal pro-breast-feeding measures. }\end{array}$} \\
\hline
\end{tabular}


was reported in a study conducted in the Philippines ${ }^{26}$, suggesting that this association may be common to different regions of the world. Horta et al. ${ }^{27}$ have previously described that low-birth-weight babies tend to be breast-fed for shorter periods. Eregie ${ }^{23}$, in a study of the association between EBF and mother's age, mother's schooling and birth weight in Nigeria, found that only birth weight showed a statistically significant association with breast-feeding after controlling for the remaining variables. The study conducted in Brazil and Honduras ${ }^{22}$ found a greater duration of EBF among children born weighing $3100 \mathrm{~g}$ or more. This finding is consistent with the hypothesis that babies with lower birth weight, due to their weaker suckling, would fail to stimulate the establishment of an appropriate production of breast milk $^{28}$. In the present study, we also found that children whose follow-up was done in private network facilities had greater chance of being exclusively breast-fed than children who attended public facilities, even after controlling for socio-economic conditions and other potential confounders. However, as we shall discuss below, the multivariable model studying the interaction between contextual and individual variables and the frequency of EBF indicated that the 'negative effect' of follow-up in the public network is restricted to municipalities with a poor performance with respect to the implementation of pro-breast-feeding measures.

The lack of an association between EBF and the sociodemographic characteristics of the municipalities, especially IPRS, suggests that EBF is a phenomenon that, unlike other outcomes such as infant mortality and malnutrition, does not include 'macro-contextual' characteristics among its major determinants. The scenario changes when we analyse the influence of context in terms of the presence, in the municipalities, of pro-breastfeeding measures. By employing multilevel models, we were able to verify that, after controlling for the effects of individual variables, the total number of pro-breastfeeding measures had a positive impact on EBF, being the variable with the greatest OR in the final model.

It is also interesting to observe that the concomitant implementation of several measures was able to improve breast-feeding practice. This finding is consistent with the arguments of Giugliani ${ }^{29}$. This author concluded, based on an extensive review of the literature on strategies to increase EBF, that several measures need to be implemented simultaneously, including the amplification of educational activities, community support, labour regulations, and compliance with the Brazilian Norm for the Commercialization of Foods for Lactating Infants. It is reasonable to speculate that municipalities that develop four or more pro-breast-feeding measures would be able to remove some of the major obstacles to the practice of EBF indicated by Giugliani ${ }^{29}$.

Multilevel analysis also allowed us to test the hypothesis of whether the synthetic contextual variable total number of pro-breast-feeding measures would modify the effects of individual variables. Three statistically significant interactions were thus identified in the final model. These three interactions indicate that the implementation by municipalities of at least four pro-breast-feeding measures was able to attenuate the negative effect of two risk factors for the early termination of breast-feeding (low mother's schooling and low birth weight). Likewise, with respect to child follow-up, the implementation of at least four actions rendered follow-up in the public network a protective factor (and no longer a risk factor) for early interruption of EBF. In these three cases, evidence speaks in favour of the potential of concomitant implementation of several measures to reduce social inequalities in terms of the practice of EBF.

The present study also identified a number of groups 'susceptible' to the interruption of EBF before the 6th month of life, which may be useful for the planning of probreast-feeding measures more specific to this population. Notwithstanding, it is important to keep in mind that interventions aimed at reducing the prevalence of these 'risk factors' are often complex, and, generally speaking, are effective on medium- or long-term bases.

We hope that the positive impact of pro-breast-feeding measures found in the present study, along with the evidence that the implementation of a set of measures can attenuate or even annul the negative effect of individual 'risk factors' for the early termination of EBF, may serve as a further stimulus for policy-makers and health-care professionals at the municipal level.

\section{Acknowledgements}

The authors thanks Aluísio JD de Barros, from Universidade Federal de Pelotas, Brazil, for his assistance and excellent in-depth comments about the multilevel analysis.

The study was funded with resources from the Instituto de Saúde - Secretaria de Estado da Saúde de São Paulo.

\section{References}

1 Victora CG, Smith PG, Vaughan JP, Lombardi C, Fuchs SMC, Gigante LP, et al. Evidence for protection by breastfeeding against infant deaths from infectious diseases in Brazil. Lancet 1987; 2: 317-22.

2 César JA, Victora CG, Barros FC, Santos IS, Flores JA. Impact of breast feeding on admission for pneumonia during postneonatal period in Brazil: nested case-control study. British Medical Journal 1999; 318: 1316-20.

3 Betrán AP, Onis M, Lauer J, Villar J. Ecological study of effect of breastfeeding on infant mortality in Latin America. British Medical Journal 2001; 323: 303-6.

4 Sanghvi TG. Melhora da eficácia em função dos custos da promoção do aleitamento materno em maternidades. Resumo do estudo USAID/LAC HNS na América Latina 
(1992-1995). New York: United Nations Children's Fund, Nutrition Section, 1996

5 Venancio SI, Monteiro CA. A evolução da prática da amamentação nas décadas de 70 e 80. Revista Brasileira de Epidemiologia 1998; 1: 40-9.

6 Monteiro CA. Evolução da nutrição infantil nos anos 90. In Velhos e novos males da saúde no Brasil: a evolução do país e suas doenças. São Paulo: Hucitec, Nupens/USP, 2000.

7 World Health Organization (WHO). Infant and young child nutrition. 54th World Health Assembly, Resolution WHA54.2. Geneva: WHO, 2001.

8 Silva NN. Amostragem probabilística: um curso introdutório. São Paulo: Universidade de São Paulo, 1998.

9 World Health Organization (WHO), Division of Child Health and Development. Indicators for Assessing Breastfeeding Practices. Geneva: WHO, 1991.

10 Ministério da Saúde, Instituto Nacional de Alimentação e Nutrição. Programa Nacional de Incentivo ao Aleitamento Materno - PNIAM/INAN e UNICEF. Aleitamento Materno e o Município. Brasília: Ministério da Saúde, 1995.

11 Fundação SEADE [homepage]. http://www.seade.sp.gov.br, 3 June 2001

12 Silva-Ayçaguer LC. Excursão a la regresión logística en ciencias de la salud. Madrid: Ed. Diaz de Santos, 1995.

13 Diex-Roux AV. Bringing context back into epidemiology: variables and fallacies in multilevel analysis. American Journal of Public Health 1998; 88: 216-22.

14 Susser M. The logic in ecological: I. The logic of analysis. American Journal of Public Health 1994; 84: 825-9.

15 Fuchs SC, Victora CG, Fachel J. Modelo hierarquizado: uma proposta de modelagem aplicada à investigação de fatores de risco para a diarréia grave. Revista de Saúde Pública 1996; 30: $168-78$

16 Victora CG, Huttly SR, Fuchs SC, Olinto MT. The role of conceptual frameworks in epidemiological analysis: a hierarchical approach. International Journal of Epidemiology 1997; 26: 224-7.

17 Hox JJ. Applied Multilevel Analysis. Amsterdam: TTPublikaties, 1995.

18 Yang M, Rasbash J, Goldstein H, Barbosa M. MLwiN Macros for Advanced Multilevel Modelling. London: Institute of Education, 1999.

19 Hosmer DW, Lemeshow S. Applied Logistic Regression. New York: John Wiley and Sons, 1989.

20 Ministério da Saúde, Brasil. Prevalência de aleitamento materno nas capitais brasileiras e no distrito federal. Brasília: Ministério da Saúde, 2001.

21 Sociedade Civil Bem Estar Familiar no Brasil (BEMFAM). Pesquisa Nacional sobre Demografia e Saúde. Rio de Janeiro: BEMFAM, 1997 [Relatório de Pesquisa].

22 Pérez-Escamilla R, Lutter C, Segall AM, Rivera A, TrevinoSiller S, Sanghvi T. Exclusive breast-feeding duration is associated with attitudinal, socioeconomic and biocultural determinants in three Latin American countries. Journal of Nutrition 1995; 125: 2972-84

23 Eregie CO. Studies on exclusive breastfeeding: a report on associated factors in an African population. Journal of Tropical Pediatrics 1998; 44: 172-3.

24 Notzon F. Trends in infant feeding in developing countries. Pediatrics 1984; 74(Suppl.): 648-66.

25 Forman MR. Review of research on the factors associated with choice and duration of infant feeding in less-developed countries. Pediatrics 1984; 74(Suppl.): 667-94.

26 Adair LS, Popkin BM, Guikey DK. The duration of breastfeeding: how it is affected by biological, socioeconomic, demographic, health sector and food industry factors? Demography 1993; 30: 63-80.

27 Horta BL, Barros FC, Halpern R, Victora CG. Baixo peso ao nascer em duas coortes de base populacional no Sul do Brasil. Cadernos de Saúde Pública 1996; 12(Suppl. 1): $27-31$.

28 Pérez-Escamilla R, Cohen R, Brown KH, Landa-Rivera L, Canahuati J, Dewey KG. Maternal anthropometric status and lactation performance in a low-income Honduran population; evidence for the role of infants. American Journal of Clinical Nutrition 1995; 61: 528-34.

29 Giugliani ERJ. Technical consultation on infant and young child feeding. How can we increase exclusive breastfeeding, 2001 [mimeo]. 